\title{
Radioactivity concentration and heavy metal content in fuel oil and oil-ashes in Venezuela
}

\author{
H. Barros ${ }^{1}$, L. Sajo-Bohus ${ }^{2}$, J.M. Abril ${ }^{3}$ and E.D. Greaves ${ }^{2}$ \\ ${ }^{1}$ Dpto. FAMN, Facultad de Física, Universidad de Sevilla, Apdo., 41060 Sevilla, Spain \\ ${ }^{2}$ Dpto. Física, Universidad Simón Bolívar, Sartenejas, Edo. Miranda, Venezuela \\ ${ }^{3}$ Dpto. Física Aplicada I, Universidad de Sevilla, EUITA, Ctra. Utrera km 1, \\ Apdo. 41013, Sevilla, Spain
}

\begin{abstract}
Environmental radiation levels are modified in regions where the oil industrial activity is more aggressive, such as in the Zulia State and the Orinoco's Oil Belt. In these regions Venezuela is producing 1750 thousand barrels of oil from the near-to-the-surface or deep oil drilling, being its 2003 total OPEC market share 2932 thousand barrels of oil per day [1]. Petroleum constitutes an important source of energy and as the majority of natural sources it contains radionuclides and their disintegration products. The combustion of oil concentrates in the ashes those radioelements, which later enters the environment by different pathways producing adverse effects on the quality of man life. The concentration of radioelements varies greatly between oil fields, and then still requiring local survey studies in this area. Moreover due to the recent national interest in recycling processes, it becomes important to take care in the selection of materials that may contain by-products of industrial origin. In fact the oil ashes and other mining by-products are employable in the building industry. The concentration of radioactivity and heavy metals in crude oil, fuel oil $\mathrm{N}^{\circ} 6$ and the ashes from power plants were determined. The analysis includes the two major thermoelectric power plants in Venezuela, Ricardo Zuluaga on the northern seaside of Caracas and Planta Centro on the littoral of Carabobo State. The study covers different samples: fuel oil $\mathrm{N}^{\circ} 6$, heavy and medium petroleum as well as fuel Oil $\mathrm{N}^{\circ} 6$ ashes. Gamma spectrometry was used for measuring ${ }^{226} \mathrm{Ra},{ }^{214} \mathrm{~Pb},{ }^{214} \mathrm{Bi},{ }^{228} \mathrm{Ac},{ }^{212} \mathrm{~Pb},{ }^{212} \mathrm{Bi},{ }^{208} \mathrm{Tl}$ and ${ }^{40} \mathrm{~K}$, and heavy metallic cations were determined by ICP-MS, which also allows the direct determination of ${ }^{232} \mathrm{Th}$ and ${ }^{238} \mathrm{U}$. In this material (oil ashes) the total activity concentration is above $300 \mathrm{~Bq} \cdot \mathrm{kg}^{-1}$. Some criteria from the literature have been compared and used to investigate the applicability of oil ashes as an additive for building materials. The combustion concentrate also heavy metal cations, as is the case of $\mathrm{Pb}, \mathrm{Ni}, \mathrm{Mn}, \mathrm{V}, \mathrm{Zn}$ among others. The found high metal concentrations can represent an important environmental risk since the high amount of sulfates in the Venezuelan oil and ashes contributes to their dissolution and bioavailability.
\end{abstract}

\section{INTRODUCTION}

During the last years an intensive national program has been developed to determine the environmental radioactivity levels in Venezuela. Gamma dose and the radon concentrations indoors, in drinking water, in caves and in artificial cavities including the effect of radon transported to the surface with the earth gas have been studied [2-5]. To continue this task the oil and its related products should be considered. In general, oil and oil ashes content can be discriminated, on the bases of its concentration, as major elements $(\mathrm{C}, \mathrm{H}, \mathrm{O}$ and $\mathrm{N}$ with more than $10000 \mathrm{ppm})$, minor elements (Al, $\mathrm{Ca}, \mathrm{Fe}, \mathrm{K}, \mathrm{Mg}, \mathrm{Na}$ and $\mathrm{Si}$ with contents between 10000 and $1000 \mathrm{ppm}$ ) and trace elements (mainly all the remaining elements with less than $1000 \mathrm{ppm}$ ). Venezuelan oil (and may be other South American oils) are characterized by a high sulphur content, but even more by a very high (compared with other oils) vanadium content [6]. Petroleum also contains radionuclides from the 
natural radioactive series $\left({ }^{40} \mathrm{~K},{ }^{232} \mathrm{Th},{ }^{235} \mathrm{U}\right.$ and $\left.{ }^{238} \mathrm{U}\right)$ and their disintegration products. Some of these elements, depending on their concentrations and chemical forms, can represent an important environmental risk, either due to its toxicity or because of its radiological impact.

A great variety of metallic compounds are present in emissions from combustion processes, notably those from residual oil fly ash [7]. It has shown [8] that the key factor contributing to adverse health impact may be the amount of water-soluble (bioavailable) metals present in the material. The EPA has presented a detailed compilation of data used to characterize fossil fuel combustion wastes [9]. However, still a lack of information about the by-products from the oil industry in Venezuela. The dispersion of fly ashes, the accumulation of considerable amounts of ashes in big piles around the power plants and their use in the building industrie clould represent toxic or radiological risks. High dose rates indoors may arise from high activities of natural radionuclides in building materials, especially when industrial by-products are used [10]. Among the by-products with high natural radioactivity, which produces such effect, the most common are ashes from coal or oil fired power plants, alum shale and phosphogypsum [11]. Therefore, it is important to characterize the oil and oil ashes, particularly in the areas where ash production or storage is undertaken at big scale. It is also necessary to asses the potential bioavailability of their associated pollutants and study the possible uses that can be assigned to such by-products.

\section{MATERIAL AND METHODS}

\subsection{Sampling sites and samples}

The two major thermoelectric power plants in Venezuela are "Ricardo Zuluaga" on the northern seaside of Caracas and "Planta Centro" on the coast of Carabobo State (central coast) and they were selected for this study. In the plant "Ricardo Zuluaga" two kinds of fuels are usually burned to produce electricity: natural gas and fuel oil $\mathrm{N}^{\circ} 6$; we selected the unities that burn fuel oil and collected samples of two types: fuel oil No. 6 and ashes. Additionally samples of medium and heavy crude were collected from oil fields near San Tomé in the northeastern region (see map for location of the selected sites).

\subsection{Gamma spectometry of the determination of natural radioactivity}

Samples were homogenised and measured in cylindrical containers with known geometry. The analysis was performed using a coaxial high purity Ge detector with a resolution of $1.9 \mathrm{keV}$ for the ${ }^{60} \mathrm{Co}$ peak of $1.33 \mathrm{MeV}$ and a relative efficiency of the $12 \%$, supplied by CANBERRA (Meriden, CT USA) it is shielded with $5 \mathrm{~cm}$ of lead, $2 \mathrm{~mm}$ of cooper and $2 \mathrm{~mm}$ acetate. The analysis of the spectrum was performed in the ussual manner using two different programs (ACTAN and DIMEN) in order to avoid wrong integral calculations in the case of low counting rates. When it was possible (only for some radioelements) the radionuclide specific efficiency method was also applied to reduce the uncertainty in gamma ray intensities, as well as the influence of coincidence summation of the emitting gamma photons. To determinate the curve of efficiency, two IAEA references were used: IAEA 300 and IAEA 368 [12]. These calibration samples were measured in identical geometry for the radionuclides of interest with long half-lives such as: ${ }^{241} \mathrm{Am},{ }^{235} \mathrm{U},{ }^{134} \mathrm{Cs},{ }^{137} \mathrm{Cs}$ and ${ }^{40} \mathrm{~K}$ covering the energies of interest from 59 until $1460 \mathrm{KeV}$. This study included other IAEA reference materials: IAEA 152 and 135, with densities similar to the samples to be measured [13] to evaluate the influence of the matrix effect (self absorption) on the analytical method.

The total uncertainty of the radioactivity levels was calculated by propagation of the systematic and counting errors. The systematic errors in the efficiency calibration ranged from 0.5 to $3 \%$ and the counting errors were up to $8 \%$. The main radionuclides considered in dwelling dose calculations, are 
${ }^{226} \mathrm{Ra},{ }^{232} \mathrm{Th}$ and ${ }^{40} \mathrm{~K}$. The relevance often given to ${ }^{226} \mathrm{Ra}$ is due to ${ }^{222} \mathrm{Rn}$ exhalation and not only related to its own gamma emmision $(186 \mathrm{keV})$. Other radionuclides of the uranium series such as ${ }^{238} \mathrm{U}$ and ${ }^{210} \mathrm{~Pb}$, emitting low energy photons, are not determined in many scientific works assuming that its contribution to the dose is low. The above assumption is seldom checked mainly because of the difficulties in the analysis of low energy photons by gamma spectrometry [14]. Among the techniques used to solve that kind of problem, one is based on the direct determination of ${ }^{226} \mathrm{Ra}$ and ${ }^{235} \mathrm{U}$ from the analysis of the multiplet photopeak at $186.25+185.75 \mathrm{keV}$. However, for that purpose it is needed not only a high resolution in energy, but also a good counting statistics (that means a relatively high activity and/or a very low background). Some authors assume secular equilibrium to facilitate the radiometric determinations, and certainly in oil samples it could exists, but this assumption is not valid especially in the case of industrial byproducts, as the fly-ash and bottom-ash (slag) from power plants. The disequilibrium among the isotopes of the natural series is caused by the combustion process, due to the different physical and chemical properties of the uranium, radium and lead [14].

In the present paper we determine directly the ${ }^{232} \mathrm{Th},{ }^{235} \mathrm{U}$ and ${ }^{238} \mathrm{U}$ concentrations by ICP-MS. It allows the unambiguous determination of radium since the contribution of uranium to the $186 \mathrm{keV}$ photopeak (which can not be resolved with our HPGe detector) can be calculated with high precision. The amount of ${ }^{40} \mathrm{~K}$ was measured through the $1460.75 \mathrm{keV}$ photo-peak. The ${ }^{232} \mathrm{Th}$ content was calculated as the weighted mean value of ${ }^{228} \mathrm{Ra}$ concentration (measured as ${ }^{228} \mathrm{Ac} ; 911.1,968.9$ and $338.4 \mathrm{keV}$ ) and ${ }^{228} \mathrm{Th}$ concentration (measured as decay products in equilibrium, i.e. ${ }^{212} \mathrm{~Pb}$, using 238.6 and $300 \mathrm{keV}$ peaks, ${ }^{212} \mathrm{Bi}$, using $727 \mathrm{keV}$ and ${ }^{208} \mathrm{Tl}$, using $2614,583.1$ and $860 \mathrm{keV}$ ). The ${ }^{210} \mathrm{~Pb}$ activity was determined using its $46.54 \mathrm{keV}$ photons.

\subsection{Sample preparation and Microwave digestions}

The importance in the determination of the oil ash metal content and their bioavailability rely in their high metal concentrations and in the efficiency of its dissolution mechanisms in the environment. I is well known that a digestion with a mix of several acids (e.g. $\mathrm{HNO}_{3}, \mathrm{HCl}, \mathrm{H}_{2} \mathrm{SO}_{4}$ ) are necessary to dissolve the minerals and carbonaceous materials and to extract all the elements contained in oil and its ashes. However, measures should be taken to avoid the loss of volatile elements when the materials are subject to high temperatures during an open vessel acid attack. It have been found [15] that a microwave closed vessel $\mathrm{HNO}_{3}$ leaching was more reliable to quantify As and $\mathrm{Se}$ (which form volatile species). But in general, a sealed microwave digestion method using nitric acid only cannot break down silicates, which harbour many trace elements. However, the fraction of elements directly bioavailable can be dissolved by the effect of the water in the actual environmental conditions at which the leaching occurs. Some authors [16] supported that when the ashes enter in contact with water immediately transfers their strong primary acidity content to it, resulting in highly acid $\mathrm{pH}$ values as well as significant concentrations of heavy metals. It is to be noted that both oxides and sulphates are present in the ash and that the relative prevalence of one or the other causes low (for oxides) or high (for sulphates) percentages of leaching in water [16]. Some works [17] have reported that high-S oil ashes are enriched in $\mathrm{Ni}$ by a factor of about 2 relative to the low-S oil ashes. It could be particularly important in Venezuelan oil ashes, which are rich in sulphates.

Under weathering action the $\mathrm{pH}$-sensible and the oxidizable fractions may become bioavailable, and these fractions are truly extracted with a high temperature nitric acid leaching. Also we avoid the use $\mathrm{HCl}$ to kept as low as possible the polyatomic interferences that usually chlorine originates (e.g. ${ }^{35} \mathrm{Cl}^{40} \mathrm{Ar}$, a typical interference for ${ }^{75} \mathrm{As}$ ). So, in order to evaluate the possible environmental impact of accidental releases of oil and oil ash dispersion (regarded to heavy metals) a microwave $\mathrm{HNO}_{3}$ digestion was undertaken for all the samples to be isotopically characterized. The final solutions were filtered $(2.5 \mu \mathrm{m}$ mesh) to eliminate the remaining solids, so the total dissolved solid does not have to pass the $0.2 \%$. 


\subsection{Measurements by ICP-MS}

ICP-MS is extremely sensitive and the efficient ionisation by means of a plasma coupled with the sensitive detection of the mass spectrometer results, at its best, in parts per trillion detection limits that are generally 2-3 orders of magnitude lower than those in ICP-AES. ICP-MS analyses were performed on a quadrupolar ICP-MS (ThermoElemental X7 series, UK).

The instrumental parameters and operating conditions are listed in Table I. The background was checked at atomic masses 5 and 220. The instrument was optimised for multi-element determination from ${ }^{9} \mathrm{Be}$ to ${ }^{238} \mathrm{U}$. The ion lenses were optimised simultaneously monitoring isotopes of low $\left({ }^{9} \mathrm{Be}\right)$ middle $\left({ }^{115} \mathrm{In}\right)$ and high $\left({ }^{238} \mathrm{U}\right)$ masses so that the count rate is suited to achieve the best possible compromise across the mass range considered. The dynamic range of the technique allows linear calibration curves over five or six orders of magnitude, therefore quantification was performed for all the elements by using external standard calibration curves drawn through the blank and 5 more points, using multielement aqueous standard solutions in $2 \% \mathrm{HNO}_{3}$. Each sample determination was the mean of three separate sequential determinations. Signal drift was monitored by the on line dilution of internal standard $\left(5 \mathrm{ppb}{ }^{115} \mathrm{In},{ }^{209} \mathrm{Bi}\right)$ and a linear drift correction was applied to each main mass scan. The sample list consisted of a calibration blank and a procedural blank, calibration solutions, three replicants of each oil or ash samples as unknowns and quality control samples. The blank and calibration solutions are inserted every 20 samples to reduce the accumulative drift. The results are the mean values of the three measurements, since the precision of the technique is much more high for individual samples. Taking into account both instrumental sensitivity and sample preparation, the LOQs are calculated as the concentration equal to 10 times the standard deviation of the background signal (procedural blank) multiplied by the dilution factor. The variability of analytical blanks and instrument performance were calculated as the mean of the LOQ established in each analytical session.

Table 1. ICP-MS System Parameters.

\begin{tabular}{ll}
\hline ICP-MS & $\begin{array}{l}\text { X7 SERIES Thermo } \\
\text { Elemental (U.K) }\end{array}$ \\
Detector & $\begin{array}{l}\text { Peak jump 60 sweeps } \\
10 \text { ms dwell/peak }\end{array}$ \\
Spray & Peltier cooled impact \\
chamber & based $\left(3^{\circ} \mathrm{C}\right)$ \\
ICP & Solid state $27 \mathrm{MHz}$ \\
& $1200 \mathrm{~W}$ \\
Nebulizer & Concentric \\
Torch & $\begin{array}{l}1.5 \mathrm{~mm} \text { (quartz) } \\
\text { Gasow }\end{array}$ \\
Coolant 12, Aux 0.7 \\
flow & and Nebulizer $0.9(\mathrm{~L} / \mathrm{min})$ \\
\hline
\end{tabular}

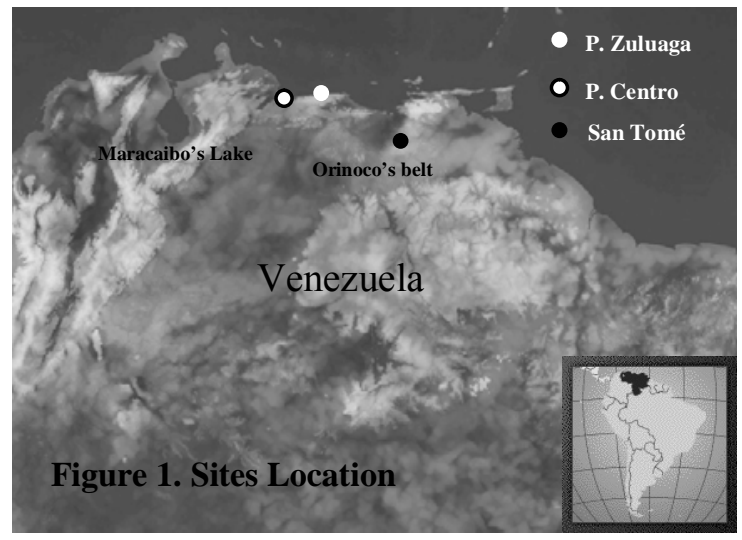

\section{RESULTS AND DISCUSSION}

\subsection{Concentration of radionuclides and criteria for applicability of ashes as building materials}

The natural radioactivity levels measured in a selection of oil, fuel oil $\mathrm{N}^{\mathrm{o}} 6$ and ashes was performed, these levels seems to not represent a high radiological risk as compared with other reports [9]. Results for fuel oil $\mathrm{N}^{\circ} 6$ ash are presented in Table II. The ${ }^{232} \mathrm{Th}$ and the U were measured by ICPMS, and in all the samples the ${ }^{235} / 238$ ratio was preserved (0.0072) then the contribution of ${ }^{235} \mathrm{U}$ to the ${ }^{226} \mathrm{Ra}$ peak of 
$186.25 \mathrm{keV}$ was confirm to be less than $1 \%$ in all the cases. It allowed the unambiguous determination of the radium that was used for the safety criteria evaluation. The ${ }^{232} \mathrm{Th}$ was also determined as the weighted mean value of ${ }^{228} \mathrm{Ra}$ concentration (measured as ${ }^{228} \mathrm{Ac} ; 911.1 \mathrm{keV}$ ) and ${ }^{228} \mathrm{Th}$ concentration (measured as decay products in equilibrium, i.e. ${ }^{212} \mathrm{~Pb}, 238.6 \mathrm{keV},{ }^{212} \mathrm{Bi}, 727 \mathrm{keV}$ and ${ }^{208} \mathrm{Tl}, 860 \mathrm{keV}$ ) and it was confirmed that such method lead to an overestimation. The natural radioactivity of samples was varying significantly depending on their origin and disequilibrium between the series was also observed (see table II) due to the enrichment of ash in radioelements such a ${ }^{208} \mathrm{Tl}$.

Table 2. Radioactivity concentration $[\mathrm{Bq} / \mathrm{kg}]$ in ashes of burned fuel oil $\mathrm{N}^{\mathrm{o}} 6$.

\begin{tabular}{ccccccccccccccc}
\hline & ${ }^{228} \mathrm{Th}$ & ${ }^{226} \mathrm{Ra}$ & ${ }^{212} \mathrm{~Pb}$ & ${ }^{214} \mathrm{~Pb}$ & ${ }^{208} \mathrm{Tl}$ & ${ }^{214} \mathrm{Bi}$ & ${ }^{212} \mathrm{Bi}$ & ${ }^{228} \mathrm{Ac}$ & ${ }^{232} \mathrm{Th}^{+}$ & ${ }^{232} \mathrm{Th}^{*}$ & ${ }^{235} \mathrm{U}^{+}$ & ${ }^{238} \mathrm{U}^{+}$ & ${ }^{40} \mathrm{~K}$ \\
\cline { 2 - 5 } & 112 & 16 & 63 & 17 & 27 & 16,7 & 70 & 14 & 0,48 & 38 & $410^{-4}$ & 0,65 & 20 \\
$\%$ & 14 & 14 & 10 & 5 & 35 & 6 & 10 & 10 & 3 & 10 & 6 & 3,6 & 5 \\
\hline
\end{tabular}

${ }^{+}$The Th and U were directly measured by ICP-MS and then the activities were calculated.

* This ${ }^{232}$ Th value was obtained assuming secular equilibrium along the series and it is clearly over estimated.

Mitigation techniques have been developed and applied to reduce the indoor internal dose due (mainly) to ${ }^{222} \mathrm{Rn}$, but the only practicable method to reduce the indoor external dose due to building materials is to select materials with a lower radionuclide content before construction. Therefore, different criteria have been established by different authors and national or international authorities. In general, the gamma radiation of the potassium, thorium and radium are the input data, as well as the dose due to radon. We have chosen some models that minimise the required experimental efforts to prove compliance with the established criteria. The assumed approximations are valid for the present application. The Table II shows the highest values in the present study, and it were used to verify their compliance with several criteria for safety in building materials (Table III); and following those conservative criteria the analyzed ashes can be used as an additive for the construction.

Table 3. Recommended limits for Radioactivity in Building materials.

\begin{tabular}{cccccc}
\hline${ }^{226} \mathrm{Ra}$ & ${ }^{232} \mathrm{Th}$ & ${ }^{40} \mathrm{~K}$ & Calculated Value & Maximum Value & Reference \\
\hline \multicolumn{2}{c}{ Multiplicative factor } & & & \\
\hline 0,0116 & 0,0017 & 0,00010 & 0,19 & 1 & [18] Steger \& Grün, 1999 \\
0,0027 & 0,0043 & 0,00027 & 0,05 & 1 & {$[$ [19] Zak et al. 2001 } \\
1 & - & - & $16 \mathrm{~Bq} / \mathrm{kg}$ & $185 \mathrm{~Bq} / \mathrm{kg}$ & [19] Zak et al. 2001 \\
0,0054 & 0,0039 & 0,00021 & 0,09 & 1 & [20] Beretka \& Mathew, 1985 \\
\hline
\end{tabular}

For Steger \& Grün's model the suggested preconditioned values have been used: $\rho=2350 \mathrm{~kg} / \mathrm{m}^{3}$, wall thickness $0.3 \mathrm{~m}$ and emission factor 0.1 .

\subsection{Hevy metal content and re-concentration process}

A sealed microwave digestion using nitric acid only cannot break down silicates, however the fraction of elements directly bio-available can be dissolved by the effect of the water in the actual environmental conditions, and these fractions are truly extracted with a high temperature nitric acid leaching, that is the digestion chosen in the present paper. It is to be noted that both oxides and sulfates are present in the ash and that the relative prevalence of one or the other causes low (for oxides) or high (for sulfates) percentages of leaching in water. It could be particularly important 
in Venezuelan oil ashes, which are rich in sulfates. In fact, in the case of our ash samples the total S content range $10 \%$. Due to the combustion of fuel oil $\mathrm{N}^{\circ} 6$, a re-concentration factor of 110 was observed for $212 \mathrm{~Pb}$ while a factor of 27 is obtained for $232 \mathrm{Th}$, no more information was obtained since the remaining radionuclides were under the detection limits for the fuel oil sample. In all the measurements by ICPMS the standard addition technique was used in order to avoid matrix effects. In the Table V it can be seem the heavy metal content of the different samples, then can be noted that the re-concentration factors can be as high as 6000 as in the case of $\mathrm{Mn}$.

Table 4. Heavy metals in the Oil and Ash samples.

\begin{tabular}{|c|c|c|c|c|c|c|c|c|c|c|c|c|c|}
\hline & $\mathrm{Ti}$ & V & $\mathrm{Cr}$ & $\mathrm{Mn}$ & Co & $\mathrm{Ni}$ & $\mathrm{Cu}$ & $\mathrm{Zn}$ & As & $\mathrm{Se}$ & $\mathrm{Cd}$ & $\mathrm{Sb}$ & $\mathrm{Pb}$ \\
\hline Fuel oil & 0,11 & 113 & 0,46 & 0,04 & 0,58 & 12,5 & 0,60 & 0,69 & $L L D$ & $L L D$ & $L L D$ & 0,028 & 0,16 \\
\hline$\%$ RSD & 73 & 8 & 6 & 12 & 23 & 4 & 5 & 8 & & & & 12 & 4 \\
\hline Crude & 11 & 15 & 13 & 15 & 4,5 & 20 & 46 & 56 & 0,39 & 0,46 & 0,073 & 0,032 & 9,2 \\
\hline$\% \mathrm{RSD}$ & 8 & 12 & 8 & 7 & 6 & 8 & 7 & 8 & 7 & 17 & 11 & 10 & 7 \\
\hline Medium & 0,12 & 225 & 0,62 & 0,18 & 6,3 & 16 & 0,47 & 1,76 & 0,07 & $L L D$ & 0,005 & 0,024 & 0,18 \\
\hline$\%$ RSD & 70 & 11 & 0 & 7 & 7 & 2 & 4 & 5 & 29 & & 24 & 6 & 5 \\
\hline Heavy O. & 1,9 & 250 & 0,72 & 0,15 & 3,3 & 39 & 0,50 & 0,27 & $L L D$ & 0,06 & 0,010 & $L L D$ & 0,28 \\
\hline$\%$ RSD & 12 & 7 & 11 & 12 & 16 & 8 & 10 & 50 & & 68 & 32 & & 6 \\
\hline Ash & 47 & $27 \mathrm{k}$ & 107 & 258 & 156 & 4824 & 180 & 634 & 2,6 & 1,90 & 1,99 & 0,97 & 87 \\
\hline$\%$ RSD & 1 & 9 & 2 & 4 & 6 & 5 & 4 & 3 & 2 & 10 & 1 & 2 & 4 \\
\hline Factor $^{+}$ & 412 & 240 & 235 & 6059 & 271 & 385 & 302 & 915 & 86 & 475 & 200 & 34 & 556 \\
\hline
\end{tabular}

\section{CONCLUSION}

In a case of our interest, leaching of ashes in the storage piles (due to the rain action), their main effects will be related to their bulk properties. Therefore it is important to characterize the oil and oil ashes, particularly in the areas where ash production or storage is undertaken at big scale. For this propose it is also necessary to asses the potential bioavailability of their associated pollutants. Finally in a preliminary test a water leaching shows that up to $570 \mu \mathrm{g} / \mathrm{g}$ of vanadium $(2 \%$ of the total) can be released $(20 \mathrm{ml}$ of Millipore water and 1 gram of dry ashes) in just 12 hours. Then, once the methodology has been established, speciation and bio-availability assays are currently being undertaken. We suggest that the use of this ash in the building industry is safe from the radiological perspective and is recommended to diminish the environmental impact caused by their heavy metal content. 


\section{References}

[1] PDVSA 2004.

[2] Liendo J, Sajó-Bohus L, Pálfalvi J, Greaves E. and Gomez N. Radiat Measur 28 (1997) 729-732.

[3] Palacios, D., Castro, D., Perez, Urbani, F., Sajo-Bohus, L., LaBrecque, J.J. J. Radioanal. Nucl. Chem. 241 (1998) 69-73.

[4] Sajo-Bohus, L.; Palfalvi, J.; Urbani, F.; Castro, D.; Greaves, E.; Liendo, J. Radiat Measur. 31 (1999) 283-286.

[5] LaBrecque J. J and Cordoves P. R. J. Radioanal. Nucl. Chem. 260 (2004) 255-264.

[6] Primerano P, Campisi I, Di Pasquale S and Corigliano F. Atmos Environm. 33 (1999) 3551-3558.

[7] Samet J. M, Silbajoris R, Huang T. and Jasper I. Environm. Health Perspec. 110 (2002) 985-990.

[8] Huggins F, Huffman G, Linakand W. and Miller C. A. Environ. Sci. Technol 38 (2004) 1836-1842.

[9] US EPA. Report to Congress 1999. Wastes from the Combustion of Fossil Fuels. Volume 2 - Methods, Findings, and Recommendations.

[10] Stoulos S, Manolopoulou M, Papastefanou C. J. Environ. Rad. 69 (2003) 225-240.

[11] UNSCEAR. 1998. United Nations Scientific Committee on the Effects of Atomic Radiation. Sources and Effects of Ionizing Radiation.

[12] AQCS, Intercomparison Runs Reference Materials. 1991, 1992 and 1994-95. IAEA. Vienna.

[13] Barros H. Diploma-Thesis. Universidad Simon Bolivar, Physics Dept., Venezuela 1998 (in spanish).

[14] Petropoulos N. P, Anagnostakis M. J. and Simopoulos S. E. J. Environ Rad. 61 (2002) 257-269.

[15] Lachas H, Richaud R, Jarvis K. E, Herod A. A, Dugwell D. R. and Kandiyoti R. Analyst 124 (1999) $177-184$.

[16] Primerano P, Di Pascuale S. Mavilia L. and Corigliano F. Atmos Emviron. 32 (1998) 225-230.

[17] Galbreath K. C, Zygarlicke C. J, Huggins F. E, Huffman G. P. and Wong J. L. Energy \& Fuels. 12 (1998) 818-822.

[18] Steger F. "Radioactivity in Building Materials ÖNORM S 5200: A Standard in Austria to Limit to Limit Natural Radioactivity in Building Materials." Radon in the Living Environment, Athens, Greece. 19-23 April 1999, and Grün K. pp. 219-224.

[19] Zak A, Biernacka M, Lipinski P, Mamont-Ciesla K. Sci Total Environ. 272 (2001) 105-106.

[20] Beretka J. \& Mathew P. J. Health Physics. 48 (1985) 87-95. 